\title{
Quantum-chemical study of molecular structure and relative stability of trans and cis isomers of model anilide derivatives
}

\author{
Denisa Cagardová, Peter Poliak, Vladimír Lukeš \\ Department of Chemical Physics, Faculty of Chemical and Food Technology, \\ Slovak University of Technology in Bratislava, Radlinského 9, Bratislava, SK-81237 Slovakia \\ denisa.cagardova@stuba.sk
}

\begin{abstract}
Derivatives of anilide were studied systematically by the density functional theory (DFT) using the B3LYP hybrid functional and the $6-311+\mathrm{G}(3 \mathrm{df}, 2 \mathrm{p})$ basis set. Characteristic frequencies of $\mathrm{N}-\mathrm{H}$ and $\mathrm{C}=\mathrm{O}$ stretching modes for cis and trans conformers distinguishing were compared with available experimental and theoretical data. Effect of substitution in ortho position and acidic residue group is discussed with respect to the bond length changes in the aromatic ring and aromaticity indexes. Energy differences between cis and trans conformations allow estimating the effect of intramolecular hydrogen bonds stabilizing the studied conformations. The trans conformation of parent formanilide is stabilized via the $\mathrm{C}_{\text {(aromatic) }}-\mathrm{H} \cdots \mathrm{O}=\mathrm{C}$ interaction with the energy of around $4 \mathrm{~kJ} \cdot \mathrm{mol}^{-1}$. The selected anilide series represent model compounds for drug design.
\end{abstract}

Keywords: HOMED parameters, acetanilide, aromaticity, steric effect, hydrogen bonding

\section{Introduction}

One of the most important linkages in nature is the peptide bond (amide bond) binding amino acids in the formation of proteins. In recent years, formanilide has been the subject of many studies because it is the simplest aromatic molecule including a peptide bond $-\mathrm{NH}-\mathrm{CO}-$ in its structure. Secondary amides like formanilide are great theoretical models for studying conformational isomerism of the mentioned peptide group (Marochkin and Dorofeeva, 2012). Pure cis and trans isomers of secondary amides (o-methylformanilide) have been isolated by Siddal et al. for the first time (Siddal et al., 1968). Also, ab initio quantum mechanical calculations were used to study the relative stability of the two conformers of selected anilide derivatives by Ilieva (Ilieva et al., 1999).

Various anilide derivatives are successfully used in pharmacy, including the most popular paracetamol and lidocaine pills. By modification of the molecule through substitution, its properties can be modified to fit specific needs. Substitution can invoke significant changes in the molecular structure and various pharmacokinetic and pharmacodynamic parameters including hydrophobicity, acidity, solubility, reactivity and stability. In this task, quantitative description of the effect of various substitutions is crucial. In case of formanilide or acetanilide, the characteristic coplanar structure of the aromatic ring and the amidic bond exhibit cis or trans geometry. Planarity of this system depends mainly on the substituents in ortho- positions of the aromatic ring. Moreover, also cis/trans equilibrium is affected and can also be modified by substituting the acid residue of the amidic bond. Formation of intramolecular hydrogen bonds considerably affects the stability of these isomers as well.

To quantitatively describe the effect of substitution on the aromatic ring, the Hammett equation is usually applied. The Hammett equation (and its extended forms) describes a linear free-energy relationship relating reaction rates and equilibrium constants for many reactions involving benzoic acid derivatives with meta- and para-substituents (Muller, 2009). Hammett constants can be successfully used for the prediction of equilibrium and rate constants for a variety of reactions (Hansch et al., 1991; Krygowski and Stępień, 2005). Unfortunately, the Hammett equation does not account for steric effects, which are dominant in ortho substitution. For this case, a modification of the Hammett constant has been developed by Taft (Taft, 1953).

Aromaticity of the ring as another important parameter can be quantified by the means of geometry changes. Geometry-based new parametrization for the Harmonic Oscillator Model of Aromaticity (HOMA) index was defined more than 30 years ago (Frizzo and Martins, 2012) to determine aromaticity of various types of molecules. $\pi$-Electron delocalization in homo- and heteroaromatic systems can be described by this model. The concept of HOMA was taken by Jug and Koester in 1993 to propose reformulated HOMA (rHOMA), which has been applied to various cyclic and acyclic conjugated systems (Jug and Koester, 1990). Discrepancies of the rHOMA 
index led Raczyńska et al. to introduce a new Harmonic Oscillator Model of Electron Delocalization (HOMED) index (Raczyńska et al., 2010). Quantum mechanical methods have been used to estimate the bond lengths for the reference molecules as well as for the different $\pi$-electron delocalized acyclic and cyclic compounds containing $\mathrm{C}-\mathrm{C}, \mathrm{C}-\mathrm{N}$ and $\mathrm{C}-\mathrm{O}$ bonds including heteroaromatic systems. This method is more advantageous due to the error cancellation during the procedure of the HOMED estimation. In the next modification, normalization constant, $\alpha$, is calculated using the HOMED theory for systems containing the same number of single and double bonds (even number of bonds). In 2011, the new parametrization for the HOMA index to determine aromaticity of heterocycles was introduced (Frizzo and Martins, 2011) describing HOMA for Heterocycle Electron Delocalization (HOMHED). This theory is based on the experimental data of reference molecules obtained from electron diffraction X-ray measurements.

With respect to the previously published works, the aim of our work was to present energetics of the conformational isomerism of selected model derivatives of anilide using the density functional theory (DFT). Atom numbering and molecular structures of the studied compounds are presented in Fig. 1. In this study, we focused on the substitution in ortho position and in acidic residue group to alter the properties of the anilide bond. Based on the normal modes analysis of optimal geometries, the characteristic frequencies distinguishing cis and trans conformers were determined and compared with available experimental and theoretical data. Finally, the role of intramolecular hydrogen bonds and steric effect of the substituents was analyzed.

\section{Computational details}

All calculations were performed using the Gaussian 09 program package (Frisch et al., 2013). Density functional theory (DFT) with the hybrid exchangecorrelation B3LYP functional (Becke's three

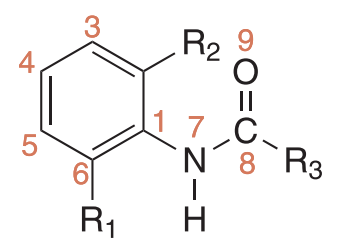

$\mathrm{R}_{1}=\mathrm{H}, \mathrm{F}, \mathrm{Me}$

$\mathrm{R}_{2}=\mathrm{H}, \mathrm{F}, \mathrm{Me}$

$\mathrm{R}_{3}=\mathrm{H}, \mathrm{F}, \mathrm{Me}, \mathrm{Cl}, \mathrm{Br}, \mathrm{CCl}_{3}, \mathrm{CF}_{3}$

$\mathbf{R}_{1} \mathbf{R}_{2} \mathbf{R}_{3} t$ parameter, Lee-Yang-Parr) (Lee et al., 1988; Becke, 1988) combination were applied. Geometries of studied molecules were optimized in the gas-phase using the $6-311+\mathrm{G}(3 \mathrm{df}, 2 \mathrm{p})$ basis set without fixing any internal coordinates. Final structures were confirmed to be real minima by vibrational analysis (no imaginary frequency). Visualization was done using the Molekel program package (Flukiger et al., 2000). Theoretical frequencies of the $\mathrm{N}-\mathrm{H}$ and $\mathrm{C}=\mathrm{O}$ stretching modes were obtained by vibrational analysis. Corrected values were calculated by multiplying calculated frequencies by a correction factor of 0.8933. $\pi$-Electron delocalization of the studied derivatives of formanilide was determined by HOMED parameters

$$
\mathrm{HOMED}=1-\frac{1}{n} \alpha_{\mathrm{CC}} \sum\left[\left(R(\mathrm{CG})_{o}-R_{i}\right)\right]^{2}
$$

where parameter $R_{\mathrm{i}}$ is the $i$-th bond length in the studied aromatic ring. In case of an even number of bonds, the normalization constant, $\alpha_{\mathrm{CC}}$, from the HOMED theory reduces to the rHOMA normalization constant, $\alpha$ (Raczyńska et al., 2010). The normalization constant, $\alpha$, for each type of bond was calculated according to the rHOMA theory from Eq. 2 (Frizzo and Martins, 2012)

$$
\alpha=2\left\{\left(R_{o}-R_{s}\right)^{2}+\left(R_{o}-R_{d}\right)^{2}\right\}^{-1}
$$

where $R_{\mathrm{o}}$ is the reference conjugated bond length in optimized geometry of an ideal aromatic molecule, benzene, $R_{\mathrm{s}}$ is the reference single bond length in ethane and $R_{\mathrm{d}}$ is the reference double bond length in ethene. Values found for the normalization constant, $\alpha$, for each type of bond were calculated using the values of reference bond lengths $\left(R_{\mathrm{o}}=1.391 \AA\right.$, $R_{\mathrm{s}}=1.527 \AA$ and $R_{\mathrm{d}}=1.325 \AA$ ) obtained from the optimized geometry of benzene, ethane and ethene using the same DFT approach as for the studied molecules. HOMED parameters are based on the optimal bond lengths obtained from quantum chemical calculations, while the rHOMA theory employs bond lengths determined by X-ray diffraction.

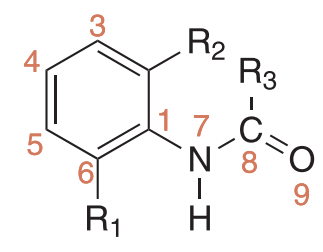

$\mathbf{R}_{1} \mathbf{R}_{2} \mathbf{R}_{3} c$

Fig. 1 Schematic structures, atom numbering and notation of studied trans and cis isomers. 


\section{Results and Discussion}

From the structural point of view, formanilide represents a parent molecule (Fig. 1). For the ortho substitution, fluorine atom as an electron withdrawing atom is sterically almost identical to hydrogen and thus, intramolecular steric effect is minimized. On the other hand, as the electron donor substituent, methyl group was selected as the smallest candidate with the smallest steric effect. Intramolecular hydrogen bonding was studied by electron withdrawing or electron donor $R_{3}$ substitution to modulate the strength of these bonds (Tab. 1). Non-substituted formanilide and acetanilide have co-planar geometry due to extended electron conjugation between the aromatic ring nitrogen lone pair and the $\mathrm{C}=\mathrm{O}$ group. This conjugation can be enhanced or diminished by a substitution on the aromatic ring or terminal group of the amidic bond. Species labeled as $\mathbf{H F R}_{\mathbf{3}}$ and $\mathbf{F H R}$ are two distinct conformers of the same structure. They correspond to local minima obtained by optimization of the two possible geometries (HFH and FHH in Fig. 2). In the HFH geometry, strong repulsive interactions between the fluorine and oxygen atoms were observed but no hydrogen bond in the trans form. However, one stabilizing $\mathrm{C}-\mathrm{H} \cdots \mathrm{F}$ hydrogen bond and weaker repulsion forces were observed in the cis form. On the other hand, trans form of the FHH geometry is stabilized via two hydrogen bonds $(\mathrm{C}-\mathrm{H} \cdots \mathrm{O}$ and $\mathrm{N}-\mathrm{H} \cdots \mathrm{F})$. Cis form contains only the $\mathrm{N}-\mathrm{H} \cdots \mathrm{F}$ hydrogen bond. Considering the total electronic energies of optimized substituted molecules, the most probable conformers can be determined. In Tab. 1, DFT values of total electronic energy and energy difference $\Delta E$ between cis and trans geometric isomers are presented. A negative value of $\Delta E$ indicates that the cis form is more energetically preferred. For the most studied compounds, trans form is favored; the only exception is fluorine-substituted 2-fluoroformanilide and 2,6difluoroformanilide where cis form is more stable ( $\mathbf{H F H} \boldsymbol{c}$ and $\mathbf{F F H} \boldsymbol{c})$. In case of FFHc, two hydrogen bonds were identified between fluorine atoms of the aromatic ring and both hydrogens of the amidic group. Oxygen and fluorine atoms are highly electronegative and there are strong repulsive forces in the trans form of this molecule (as in $\mathbf{H F H} \boldsymbol{t}$ and FFH $t$ ). According to the Boltzmann distribution, the population of HFH $\boldsymbol{t}$ and FFH $\boldsymbol{t}$ at $300 \mathrm{~K}$ is expected to be between 90 and $94 \%$ compared to the cis forms. As shown in Fig. 2, a strong steric interaction between oxygen and fluorine atoms due to the ortho-fluorine substitution of formanilide causes an increase of the dihedral angle (from planar starting point) in HFHt. Dihedral angle C6-C1-N7-C8, which represents the rotation of the aromatic ring with respect to the $-\mathrm{CO}-\mathrm{NH}-$ plane, reached the value of $-123^{\circ}$ in $\mathbf{H F H} t$. Repulsive forces between oxygen and fluorine atoms in the cis form are suppressed because of greater distance between these atoms. In $\mathbf{H F H} \boldsymbol{c}$, also intramolecular hydrogen bonds between oxygen of the carbonyl group and o-hydrogen of phenyl were observed to stabilize the isomer. Moreover, experimentally significant population of the cis form (more than $5 \%$ ) at $300 \mathrm{~K}$ has been predicted also for $\mathbf{H H H}, \mathbf{M e}_{2} \mathbf{H}, \mathbf{H F H}, \mathbf{H F M e}$, HFF, HFCl, FFMe and FFF. In case of $\mathbf{M e}_{2} \mathbf{H}$ and

Table 1. Theoretical gas-phase B3LYP 6-311+G(3df,2p) total electronic energies of studied anilide derivatives. $\Delta E$ stands for energy difference between the cis and trans isomer.

\begin{tabular}{|c|c|c|c|c|c|c|c|}
\hline Molecule & $E_{d} /$ Hartree & $E_{\ell} /$ Hartree & $\Delta E / \mathrm{kJ} \cdot \mathrm{mol}^{-1}$ & Molecule & $E_{d} /$ Hartree & $E_{t} /$ Hartree & $\Delta E / \mathrm{kJ} \cdot \mathrm{mol}^{-1}$ \\
\hline HHH & -401.085091 & -401.086621 & 4.0 & FFH & -599.627578 & -599.625540 & -5.3 \\
\hline HHMe & -440.417791 & -440.422353 & 12.0 & FFMe & -638.960735 & -638.962214 & 3.9 \\
\hline $\mathrm{HHCCl}_{3}$ & -1819.260603 & -1819.274920 & 37.6 & $\mathrm{FFCCl}_{3}$ & -2017.802910 & -2017.813485 & 27.8 \\
\hline $\mathrm{HHCF}_{3}$ & -738.242430 & -738.252430 & 25.9 & $\mathrm{FFCF}_{3}$ & -936.784294 & -936.790458 & 16.2 \\
\hline HHF & -500.376693 & -500.381100 & 11.6 & FFF & -698.917684 & -698.919103 & 3.7 \\
\hline HHCl & -860.718387 & -860.726063 & 20.2 & FFCl & -1059.260470 & -1059.264125 & 9.6 \\
\hline HHBr & -2974.636573 & -2974.645182 & 22.6 & FFBr & -3173.178655 & -3173.183064 & 11.6 \\
\hline $\mathbf{M e}_{2} \mathbf{H}$ & -479.741467 & -479.741558 & 0.2 & & & & \\
\hline FHH & -500.358168 & -500.360875 & 7.1 & HFH & -500.355757 & -500.353113 & -6.9 \\
\hline FHMe & -539.690501 & -539.697041 & 17.2 & HFMe & -539.689302 & -539.689467 & 0.4 \\
\hline $\mathrm{FHCCl}_{3}$ & -1918.532702 & -1918.548374 & 41.1 & $\mathrm{HFCCl}_{3}$ & -1918.532702 & -1918.541863 & 24.1 \\
\hline $\mathbf{F H C F}_{3}$ & -837.514294 & -837.525665 & 29.9 & $\mathbf{H F C F}_{3}$ & -837.514294 & -837.518975 & 12.3 \\
\hline FHF & -599.649916 & -599.654581 & 12.2 & HFF & -599.646544 & -599.647589 & 2.7 \\
\hline FHCl & -959.990388 & -959.999312 & 23.4 & HFCl & -959.990388 & -959.992778 & 6.3 \\
\hline FHBr & -3073.908332 & -3073.918233 & 26.0 & HFBr & -3073.908333 & -3073.911883 & 9.3 \\
\hline
\end{tabular}




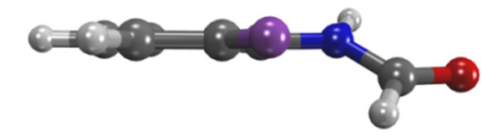

HFHc
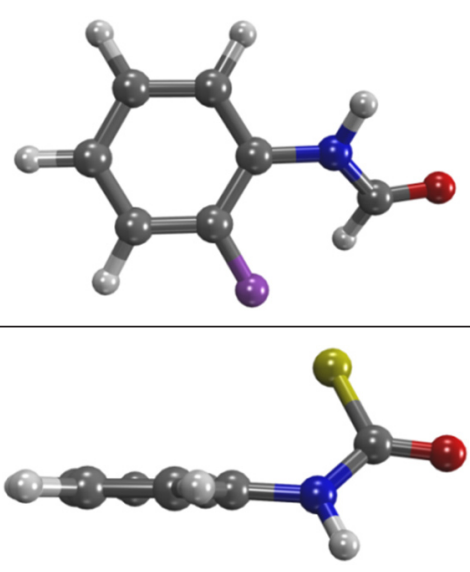

HHClc
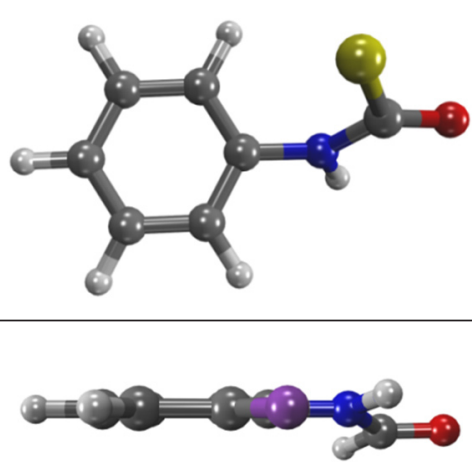

FHHc

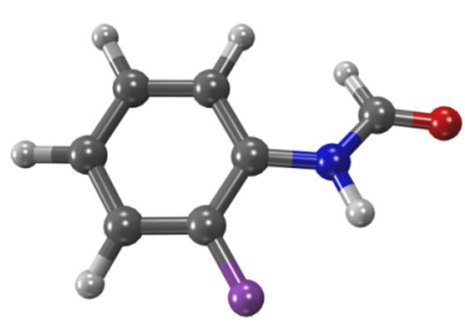

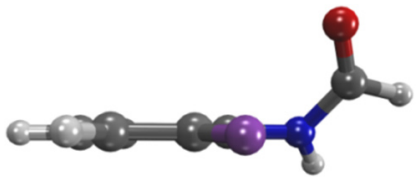

HFH $t$
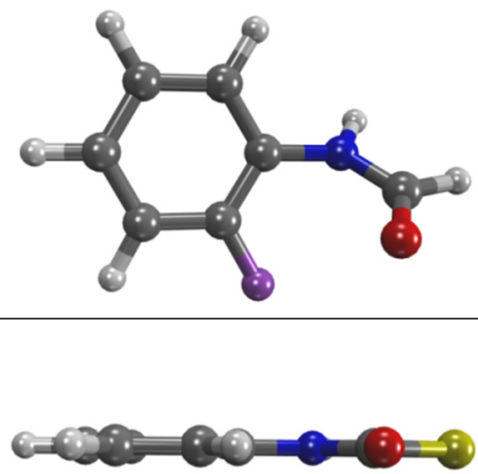

HHClt
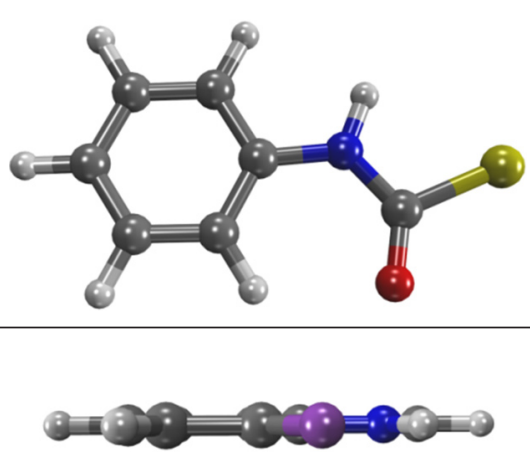

FHH $t$

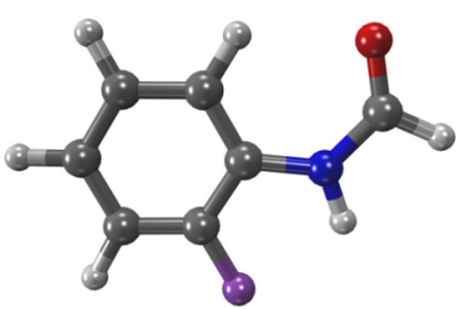

Fig. 2 Top and side views of the optimal gas-phase B3LYP structures of HFH, HHCl and FHH isomers.

HFMe, the cis/trans ratio is nearly 50:50 due to the sterical effect of the methyl group.

As it was mentioned earlier, in all studied cases with two exceptions discussed above, trans form is favored mainly because of hydrogen bonds between hydrogen and oxygen or fluorine atoms. These stabilizing interactions result in total planarity of the whole molecule with the $\mathrm{C} 6-\mathrm{C} 1-\mathrm{N} 7-\mathrm{C} 8 \mathrm{di}-$ hedral angle of around $180^{\circ}$. On the other hand, dihedral angles of cis forms differ according to steric interactions and the volume of substituents at the amide group. Large deflections of the dihedral angle from the $\mathrm{C}=\mathrm{O}$ bond plane in molecules are caused by steric repulsive interactions and absence of hydrogen bonding (Fig. 2). In case of formanilide $\mathbf{H H H}$ and generally in molecules noted as $\mathbf{H H R}_{\mathbf{3}}$, the amide group is coplanar with the aromatic ring in trans conformers due to strong $\mathrm{O} \cdots \mathrm{H}$ hydrogen bonding. In case of the $\mathbf{H H H}$ molecule, both isomers are planar. Moreover, optimal geometries of trans isomers of all studied $\mathbf{F H} \mathbf{R}_{\mathbf{3}}$ molecules resulted in total planarity (studied dihedral angle was $180^{\circ}$ ) 
due to the presence of two strong hydrogen bonds between hydrogen, fluorine and oxygen atoms (see molecule FHH in Fig. 2).

Aromaticity HOMED indexes presented in Table 2 were calculated from bond lengths using Eq. 1 and Eq. 2 for B3LYP 6-311+G(3df,2p) optimized geometries. Conformational changes from the cis to the trans form cause the HOMED parameter value to change at most by 0.002 , hence these changes can be considered as insignificant. It follows that intramolecular hydrogen bonds in formanilide derivatives stabilize the molecule, so aromaticity is preserved in all cases. As shown in Tab. 2, the most significant changes were observed for bonds $f$ and $e$ (Fig. 3), which are closest to the $\mathrm{C}=\mathrm{O}$ bond and are mostly influenced by the ortho substitution of the phenyl ring. In case of FHMe and $\mathbf{F H B r}$, significant elongation of bond length $b$ up to $0.008 \AA$ was predicted;<smiles>[R]C(=O)Nc1c([R])cccc1[R]</smiles>

Fig. 3 General structure and bond labelling in the phenyl ring of the trans conformer.

The same notation was used for the cis isomers.

however, according to their $\Delta E$ values, settling of these molecules in the cis form is improbable.

Based on the normal mode analysis, two characteristic normal modes were identified: $\mathrm{N}-\mathrm{H}$ and $\mathrm{C}=\mathrm{O}$ stretching vibrations, which reflect the substitution effect and isomerism in all studied derivatives. This selection is in agreement with the theoretical ab initio

Table 2 Bond lengths $(a-f)$ in aromatic ring of the studied molecules and HOMED parameters calculated according to Eq. 1. Parametrization constant $\alpha$ is equal to 87.108 (Eq. 2). Bond lengths are in $\AA$.

\begin{tabular}{|c|c|c|c|c|c|c|c|c|c|c|c|c|c|c|c|}
\hline & /Å & $/ \AA ̊$ & $c / \AA$ & $d / \AA$ & $e / \AA$ & $f / \AA$ & HOMED & Molecule & $a / \AA$ & b/Å & $c / \AA$ & $d / \AA$ & $e / \AA$ & $f / \AA$ & HO \\
\hline & 390 & & & & & & & & & 1.390 & & & & & \\
\hline & 86 & 391 & 89 & 390 & 97 & & & & 387 & 1.391 & 1.389 & 1.389 & 1.396 & 1.398 & \\
\hline $\mathrm{HHCCl}_{3} t$ & 385 & 391 & 389 & 90 & 396 & 1 & & $\mathrm{IHCCl}_{3} \mathrm{c}$ & 388 & 1.391 & & 390 & & 1.393 & \\
\hline HHCF $t$ & .386 & 391 & 1.389 & .390 & 1.396 & 1.397 & & $\mathrm{IHCF}_{3} \mathrm{c}$ & 1.388 & 1.391 & 1.389 & 1.390 & 1.391 & 1399 & 000 \\
\hline & .386 & 390 & 1.389 & 390 & & & & & 1.387 & 1.390 & & & & & \\
\hline & 86 & 390 & 1.389 & 390 & 1.395 & 1.397 & & & 1.390 & 1.390 & 1.391 & 1.388 & 1.392 & 1.392 & \\
\hline & 386 & 391 & 389 & 390 & 394 & 397 & & & 383 & 390 & 387 & 89 & 91 & 391 & \\
\hline & .388 & 390 & 389 & 383 & 391 & 1.394 & & Ic & 1.387 & 1.390 & 1.389 & & 387 & 1. & \\
\hline & 1.388 & 390 & 389 & 383 & 392 & 1.394 & & TM & 1.388 & 1.391 & & & & & \\
\hline $\mathrm{IFCCI}_{3} t$ & 388 & 390 & .389 & 383 & 1.394 & 1.393 & & $\mathrm{HFCCl}_{3} c$ & & 1.390 & & & & & \\
\hline $\mathrm{HFCF}_{3} t$ & 390 & 388 & 389 & 383 & 394 & 1.393 & & $\mathrm{IFCF}_{3} \mathrm{c}$ & 1.389 & 1.390 & 1.390 & 1.381 & 1.393 & 1.392 & \\
\hline HFF $t$ & 1.388 & 390 & 1.389 & 1.383 & 1.392 & 1.392 & 0.999 & HFF $c$ & 1.390 & 1.388 & 1.389 & 1.383 & 1.393 & 1.393 & 999 \\
\hline HFClt & 1.388 & 390 & 1.389 & 383 & 1.393 & 1.393 & & & 1.388 & 1.391 & 1.389 & & 1.393 & 1.393 & \\
\hline & & & & & & & & & & & & & & & \\
\hline & & & .389 & & 1.397 & 1.396 & & & 1.387 & 1.391 & 1.389 & & & & \\
\hline Met & 376 & 382 & 1.389 & 391 & 1.397 & 1.397 & & & 1.378 & 1.389 & 1.391 & & 1.393 & & \\
\hline $\mathrm{FHCCl}_{3} t$ & 1.376 & 1.391 & 1.389 & 1.390 & 1.396 & 1.396 & & $\mathrm{FHCCl}_{3} \mathrm{c}$ & 1.382 & 1.390 & 1.390 & 1.389 & 1.392 & 1.393 & 0.80 \\
\hline $\mathrm{FHCF}_{3} t$ & 1.376 & 1.391 & 1.389 & 1.390 & 1.396 & 1.396 & 0.996 & $\mathrm{FHCF}_{3} \mathrm{c}$ & 1.381 & 1.389 & 1.391 & 1.388 & 1.393 & 1.393 & 0.998 \\
\hline & & & & & & & & & & & & & & & \\
\hline & 376 & 391 & 389 & 1.390 & 395 & 95 & & & 1.381 & 389 & 1.391 & & 1.393 & & \\
\hline & 1.376 & 381 & 1.389 & 1.39 & 395 & 1.395 & & & 1.382 & 1.389 & 1.391 & 1.388 & 1.392 & 1.392 & 998 \\
\hline FFHt & 1.380 & 390 & 1.388 & 1.383 & 1.395 & 1.394 & & & 1.378 & 1.390 & 1.388 & & 1.396 & & \\
\hline & & & & & & & & & & & & & & & \\
\hline $\mathrm{FFCCl}_{3} t$ & 1.380 & 390 & 1.389 & 1.383 & 1.394 & 1.393 & & $\mathrm{FFCCl}_{3} c$ & 1.382 & 1.389 & 1.389 & 1.382 & 1.396 & 1.396 & 0.997 \\
\hline $\mathrm{FFCF}_{3} t$ & 1.380 & 1.390 & 1.389 & 1.383 & 1.394 & 1.393 & & $\mathrm{FFCF}_{3} \boldsymbol{c}$ & 1.382 & 1.389 & 1.389 & 1.382 & 1.395 & 1.395 & 0.997 \\
\hline & 1.380 & 1.390 & 1.389 & 1.383 & 1.394 & 1.393 & & & 1.381 & 1.390 & 1.389 & 1.382 & 1.395 & 1.394 & 997 \\
\hline & & & 1.389 & 383 & & & & & & & & & & & \\
\hline & 1.380 & 390 & 1.389 & 1.383 & 1.394 & 1.393 & & Frorc & 1.382 & 1.389 & 1.389 & 1.382 & 1.394 & 1.394 & 0.997 \\
\hline $\mathbf{M e}_{2} \mathbf{H} t$ & 1.395 & 1.386 & 1.388 & 1.392 & 1.404 & 1.402 & 0.995 & $\mathbf{M e}_{2} \mathbf{H c}$ & 1.396 & 1.386 & 1.388 & 1.391 & 1.405 & 1.403 & 0.994 \\
\hline
\end{tabular}



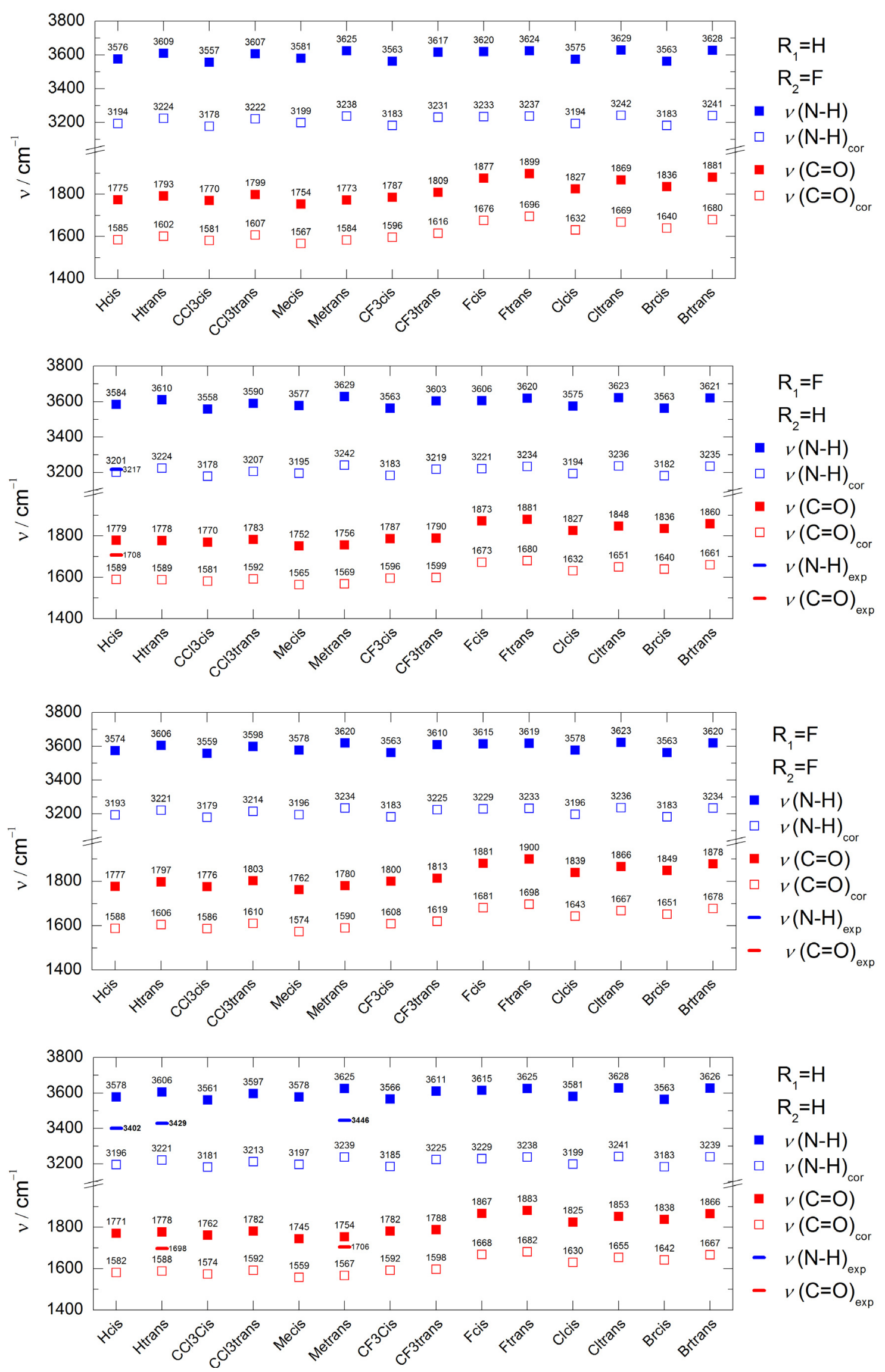

Fig. 4 Frequencies of $\mathrm{N}-\mathrm{H}$ and $\mathrm{C}=\mathrm{O}$ stretching modes obtained by the B3LYP/6-311+G(3df,2p) vibrational analysis; values were corrected by a factor of 0.8933 and compared with the experimental data (Ilieva et al., 1999; SDBSWeb, 2017). 

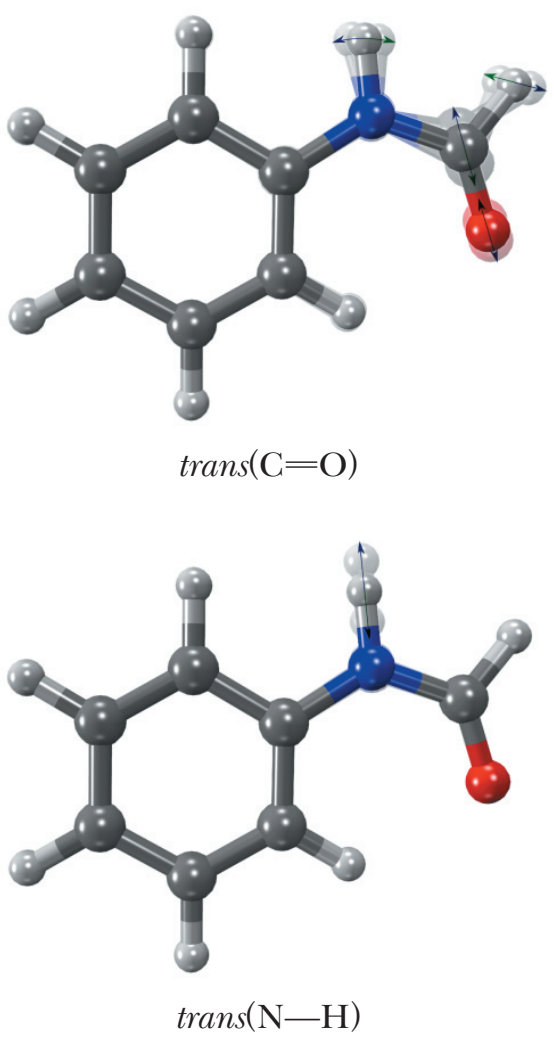

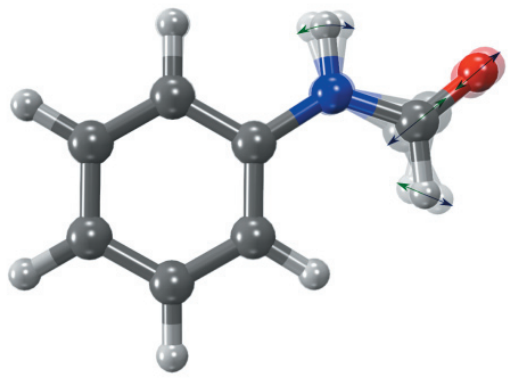

$\operatorname{cis}(\mathrm{C}=\mathrm{O})$

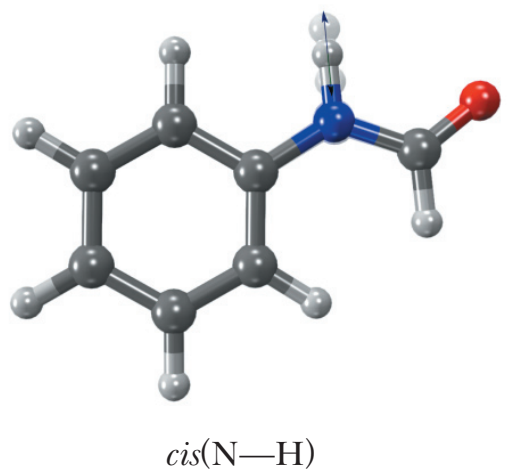

Fig. 5 Visualization of the studied $\mathrm{N}-\mathrm{H}$ and $\mathrm{C}=\mathrm{O}$ vibrational modes of trans and cis formanilide (HHH). Both positive (blue) and negative (green) displacement vectors of the strongest vibrations are depicted.

4-31G calculations and experimental observations on a smaller set of anilide derivatives (Ilieva et al., 1999; SDBSWeb, 2017). All calculated and experimental stretching frequencies are presented in Fig. 4.

As shown in Fig. 5, the band around $3600 \mathrm{~cm}^{-1}$ corresponds to almost pure $\mathrm{N}-\mathrm{H}$ stretching mode. On the other hand, the band at $1800 \mathrm{~cm}^{-1}$ consists of the $\mathrm{C}=\mathrm{O}$ stretching mode and the $\mathrm{C}-\mathrm{H} / \mathrm{N}-\mathrm{H}$ bending mode of the amidic group. Frequencies calculated for the $\mathrm{N}-\mathrm{H}$ band in the range of $3557-$ $3620 \mathrm{~cm}^{-1}$ corresponding to cis conformers are lower than those for the $\mathrm{N}-\mathrm{H}$ band corresponding to trans forms of the molecule (interval $3590-3629 \mathrm{~cm}^{-1}$ ). A similar trend was observed for vibrational frequencies of the $\mathrm{C}=\mathrm{O}$ band (calculated frequencies are in the interval of $1754-1900 \mathrm{~cm}^{-1}$ for trans form and between $1745-1881 \mathrm{~cm}^{-1}$ for cis form). The B3LYP calculated $\mathrm{N}-\mathrm{H}$ stretching mode frequencies for different conformers of the studied molecules were compared with the experimental data depicted as horizontal lines in Fig. 4. The decrease in the $\mathrm{N}-\mathrm{H}$ stretching mode frequencies in the cis structures was attributed to the direct field effect of the carbonyl group in the specific mutual orientation of the $\mathrm{C}=\mathrm{O}$ and $\mathrm{N}-\mathrm{H}$ bonds.

The DFT calculations predict almost identical absolute intensities for the $\mathrm{N}-\mathrm{H}$ stretching vibra- tions of formanilide and acetanilide associated with the $\mathrm{N}-\mathrm{H}$ stretching vibrations of the cis and trans isomers. Therefore it can be assumed that the integrated intensities in the infrared spectra quantitatively reflect the cis and trans conformational forms concentrations. Experimental data have clearly shown that the higher frequency band at $3429 \mathrm{~cm}^{-1}$ in case of formanilide and at $3453 \mathrm{~cm}^{-1}$ in case of o-methylacetanilide, is more intense. Concentration of the trans isomer is also higher, which is in agreement with the $a b$ initio estimated total energies showing higher stability of the trans conformers of formanilide and o-methylacetanilide (Ilieva et al., 1999). Additionally, it can be noted that experimental frequencies agree well with our corrected theoretically predicted frequencies.

\section{Conclusions}

Using the density functional theory, the acidic residue has been proved to influence the cis/trans equilibrium. A substitution on the phenyl ring modifies the intramolecular hydrogen bond formed between the amidic $\mathrm{C}=\mathrm{O}$ group and the hydrogen atom of the aromatic ring. For the parent formanilide molecule, the energy of this interaction is around $4 \mathrm{~kJ} \cdot \mathrm{mol}^{-1}$. Other hydrogen bonds were also identi- 
fied for the fluorine atom substitution. The steric effect for methyl derivatives was quantified. The effect of the substitution on the aromaticity can be considered to be negligible given the invariance of HOMED index values of $c$ is and trans isomers. The $\mathrm{N}-\mathrm{H}$ and $\mathrm{C}=\mathrm{O}$ stretching frequencies obtained by the vibrational analysis were compared with the experimental data. From the obtained results, it can be concluded that the applied computational method for the vibrational spectra prediction is reliable. The proposed stability predictions of anilide derivatives shed light on their reactivity and molecular shape, which can play supportive role in structure-based drug design through molecular docking or in the discovery of possible synthetic routes.

\section{Acknowledgments}

The work has been supported by Slovak Grant Agency (project VEGA 1/0594/16) and the Slovak Research and Development Agency (project APVV-15-0053). We are grateful to the HPC center at the Slovak University of Technology in Bratislava, which is a part of the Slovak Infrastructure of High Performance Computing (SIVVP project, ITMS code 26230120002, funded by the European Region Development Funds, ERDF) for providing computational time and resources.

\section{References}

Becke AD (1988) Phys. Rev. A 38: 3098-3100.

Flukiger P, Lüthi HP, Portmann S, Weber J (2000) MOLEKEL 4.3. Swiss Center for Scientific Computing: Manno, Switzerland, 2002.

Frisch MJ, Trucks GW, Schlegel HB, Scuseria GE, Robb MA, Cheeseman JR, Scalmani G, Barone V, Mennucci B, Petersson GA, Nakatsuji H, Caricato M,
Li X, Hratchian HP, Izmaylov AF, Bloino J, Zheng G, Sonnenberg JL, Hada M, Ehara M, Toyota K, Fukuda R, Hasegawa J, Ishida M, Nakajima T, Honda Y, Kitao O, Nakai H, Vreven T, Montgomery JA Jr., Peralta JE, Ogliaro F, Bearpark M, Heyd JJ, Brothers E, Kudin KN, Staroverov VN, Keith T, Kobayashi R, Normand J, Raghavachari K, Rendell A, Burant JC, Iyengar SS, Tomasi J, Cossi M, Rega N, Millam JM, Klene M, Knox JE, Cross JB, Bakken V, Adamo C, Jaramillo J, Gomperts R, Stratmann RE, Yazyev O, Austin AJ, Cammi R, Pomelli C, Ochterski JW, Martin RL, Morokuma K, Zakrzewski VG, Voth GA, Salvador P, Dannenberg JJ, Dapprich S, Daniels AD, Farkas O, Foresman JB, Ortiz JV, Cioslowski J, Fox DJ (2013) Gaussian 09, Revision D.01, Gaussian, Inc. Wallingford CT.

Frizzo CP, Martins MA (2012) Struct. Chem. 23(2): 375-380.

Hansch C, Leo A, Taft RW (1991) Chem. Rev. 91(2): $165-195$.

Ilieva S, Hadjieva B, Galabov B (1999) J. Mol. Struct. 508(1): 73-80.

Jug K, Koester AM (1990) J. Am. Chem. Soc. 112(19): 6772-6777.

Krygowski TM, Stępień BT (2005) Chem. Rev. 105(10): 3482-3512.

Lee C, Yang W, Parr RG (1988) Phys Rev B 37: 785-789.

Marochkin II, Dorofeeva OV (2013) Struct. Chem. 24(1): 233-242.

Moritz AG (1960) Spectrochim. Acta 16(10): 1176-1183.

Muller P (2009) Pure and Applied Chemistry 66(5): 1077-1184.

Raczyńska ED, Hallman M, Kolczyńska K, Stępniewski TM (2010) Symmetry 2(3): 1485-1509.

Siddall III TH, Stewart WE, Marston AL (1968) J. Phys. Chem. 72(6): 2135-2141.

SDBSWeb (2017) http://sdbs.db.aist.go.jp (National Institute of Advanced Industrial Science and Technology, date of access: 20.9. 2017)

Taft RW (1953) J. Am. Chem. Soc. 75: 4538. 